Sometimes he was very violent, and sometimes only uneasy. The length of attack varied from one day to seven or eight days. His favourite position when suffering slightly was to stand stretched to his utmost, with his chin resting on the wall in front of him as far up as he could reach. When down, he got on to his back and seemed easy in this position. Very often the bowels did not act for more than a week, and often the pulse ran down and got quite imperceptible. I more than once went of a morning with my post-mortem knife in my pocket and found him seemingly all right and feeding, as if nothing had happened. Towards the last, unless he was violent, the owner shut him in a loose-box, and gave him no medicine and no attendance. One morning he was found on his back dead. I made a post-mortem examination, and found a rupture about 2 feet long in the large colon. The bowel was very much pouched, and so thin that you could almost see through it. I picked up two calculi which had escaped through the rupture. Together they weighed about I6 lbs., and there were lots of smaller ones which would weigh collectively about io lbs.

During each attack the horse failed in flesh, but he soon picked up again and was always fat. He was always a free mover, and went a tremendous pace in a very "bouncing" manner. When viewing the calculi and the condition of the bowel in which they lay, it seemed marvellous that the latter held intact so long.

\title{
DYSURIA FROM IMPACTION OF THE RECTUM*
}

By the Same.

EARLY one morning in the autumn of this year I received an urgent message to attend a horse which was in "violent pain." I found the animal in violent pain indeed, bathed in perspiration and rolling about, the attendant being unable to keep him on his feet for more than a few minutes at a time. He had been at grass all night, and was found in this state in the morning. Occasionally he would get on his feet and try to urinate, but in this he was unsuccessful. I gave a full dose of morphia and atropine subcutaneously, got him on his feet, and endeavoured to empty the bladder with the catheter. I got the instrument round the bend of the ischial bones, but further it would not go. On passing my hand into the rectum I found it impacted with a mass of hard faces. This I manipulated and broke down, and I removed in this way, I should think, about half a bushel of hard dry fæces, composed principally of badly-masticated rye-grass stalks. Immediately the animal voided a large quantity of urine, and seemed quite easy. I gave a laxative and an enema, but there was no return of pain. During the next two or three weeks I had a number of cases exactly similar, and as soon as the rectum was emptied urine was passed freely, and pain at once ceased. All the animals were at grass, which was very much burnt up by the sun and want of moisture, and consisted chiefly of woody fibre. This undigested material accumulated in the rectum to such an extent that by its pressure on the urethra and the neck of the bladder the passage of urine was effectually suspended. 